\title{
Review
}

Neonatology

\section{Neonatal Hypoglycaemia: A Never-Ending Story?}

\author{
Nestor E. Vain ${ }^{a}$ b Florencia Chiarelli ${ }^{c}$ \\ ${ }^{a}$ School of Medicine, University of Buenos Aires, Buenos Aires, Argentina; ${ }^{b}$ Department of Paediatrics and \\ Newborn Medicine, Hospitals Sanatorio Trinidad Palermo, San Isidro and Ramos Mejía, Buenos Aires, Argentina; \\ 'Newborn Medicine, Hospital Sanatorio Trinidad Ramos Mejía, Buenos Aires, Argentina
}

\section{Keywords}

Neonatal hypoglycaemia Blood glucose threshold .

Dextrose gel · Neurodevelopmental outcome

\begin{abstract}
Neonatal hypoglycaemia is a common metabolic disorder presenting in the first days of life and one potentially preventable cause of brain injury. However, a universal approach to diagnosis and management is still lacking. The rapid decrease in blood glucose (BG) after birth triggers homeostatic mechanisms. Most episodes of hypoglycaemia are asymptomatic, and symptoms, when they occur, are nonspecific. Therefore, neonatologists are presented with the challenge of identifying infants at risk who might benefit from a rapid and effective therapy while sparing others unnecessary sampling and overtreatment. There is much controversy regarding the definition of hypoglycaemia, and one level does not fit all infants since postnatal age and clinical situations trigger different accepted thresholds for therapy. The concentration and duration of BG which cause neurological damage are unclear. Recognizing which newborn infants are at risk of hypoglycaemia and establishing protocols for treatment are essential to avoid possible deleterious effects on neurodevelopment. Early breastfeed-
\end{abstract}

ing may reduce the risk of hypoglycaemia, but in some cases, the amount of breast milk available immediately after birth is insufficient or non-existent. In these situations, other therapeutic alternatives such as oral dextrose gel may lower the risk for NICU admissions. Current guidelines continue to be based on expert opinion and weak evidence. However, malpractice litigation related to neurodevelopmental disorders is frequent in children who suffered hypoglycaemia in the neonatal period even if they had other important factors contributing to the poor outcome. This review is aimed to help the practicing paediatricians and neonatologists to comprehend neonatal hypoglycaemia from physiology to therapy, hoping it will result in a rational decision-making process in an area not sufficiently supported by evidence.

(c) 2021 S. Karger AG, Basel

\section{Introduction}

Hypoglycaemia is the most common metabolic disorder in newborns and one of the few preventable causes of brain injury. However, for many decades, the management of neonatal hypoglycaemia has been based on limited evidence [1].
Nestor E. Vain, Department of Paediatrics and Newborn Medicine Hospitals Sanatorio Trinidad Palermo, San Isidro and Ramos Mejía Professor of Paediatrics, School of Medicine, University of Buenos Aires Chenaut 1831, Buenos Aires 1426 (Argentina)

nestorvain@gmail.com 
Table 1. Causes of neonatal hypoglycaemia

\begin{tabular}{ll}
\hline Physiologic mechanism & Disorder \\
\hline $\begin{array}{l}\text { Inadequate glycogen } \\
\text { stores }\end{array}$ & $\begin{array}{l}\text { Prematurity/early term } \\
\text { Intrauterine growth restriction } \\
\text { Small for GA } \\
\text { Polycythaemia }\end{array}$ \\
\hline Increased glucose & Sepsis \\
requirements & Congenital heart disease \\
& Hypothermia \\
& Neurological problems (periventricular \\
& haemorrhage and convulsions) \\
\hline Hyper-insulinism & Infants of diabetic mother \\
& Perinatal stress \\
& Large for GA \\
& Erythroblastosis fetalis \\
& Beckwith-Wiedemann syndrome \\
& Maternal drugs ( $\beta$-blockers, anti- \\
diabetic drugs) & Nesidioblastosis \\
Congenital hyperinsulinism
\end{tabular}

The definition of hypoglycaemia has been changed over time: in the 1960 s, blood glucose (BG) concentrations as low as $20 \mathrm{mg} / \mathrm{dL}$ were tolerated; in the 1970s, up to $40 \mathrm{mg} / \mathrm{dL}$; and from 1988 onwards, a concentration of $47 \mathrm{mg} / \mathrm{dL}(2.6 \mathrm{mmol} / \mathrm{L})$ became accepted by many neonatologists [2]. In this article, we address relevant aspects of neonatal hypoglycaemia, from its pathophysiology to its treatment with special emphasis to what is known and what is not.

\section{Pathophysiology}

During foetal life, glucose crosses the placenta through a facilitated diffusion process. The foetus produces its own insulin, predominantly in response to maternal glucose concentration, but foetal insulin primarily functions to regulate growth $[3,4]$.

Neonatal Hypoglycaemia:

A Never-Ending Story?
During labour and delivery, stress induces steroid and catecholamine production, which increase cord BG concentrations $[5,6]$. At birth, placental glucose supply stops and BG concentration falls within 2-3 h of life [6], which decreases insulin secretion and activates the production of counter-regulator hormones (glucagon, catecholamines, and glucocorticoids) [7]. At this point, newborns must initiate endogenous glucose sourcing through glycogenolysis, gluconeogenesis, and activation of glucose-6-phosphate $[7,8]$. Neonatal BG concentrations at birth represent usually $70 \%$ of maternal concentration, decreasing to a nadir around $2 \mathrm{~h}$ of life and increasing after $4 \mathrm{~h}$, but continuing below adult values for several days $[9,10]$.

\section{Aetiology of Hypoglycaemia: Who Should We Screen and when Should We Check Glucose Concentrations?}

There are multiple causes of hypoglycaemia in newborns. Premature and growth-restricted infants are at increased risk because of decreased glycogen deposits compared with well-grown, term infants [5]. Late preterm and early-term neonates (gestational age [GA] 37-38 weeks) are at somewhat increased risk, probably due to the same mechanism [10].

Persistent or recurrent hypoglycaemia is frequently associated with hyperinsulinism [8]. It most commonly occurs in infants of diabetic mothers, especially those who require insulin treatment. The continuous high flow of glucose from the mother through the placenta induces the foetal pancreas to produce insulin in excess. Glucose infusion is interrupted at birth, and persistently high concentrations of insulin increase the risk of hypoglycaemia [7]. Other causes of hypoglycaemia are summarized in Table 1.

The optimal timing for checking BG after birth is not clearly determined. The AAP suggests checking initially $30 \mathrm{~min}$ after the first feed (usually in the first $2 \mathrm{~h}$ of life) in late preterm and term neonates at risk. Subsequently, checking should be adapted according to initial concentrations and the infants' characteristics. In late preterm and small-for-GA infants, some guidelines propose checking plasma glucose (PG) before each feed for $24 \mathrm{~h}$ [1]. Others check less often if BG concentrations are normal in the first screening and the infant appears to be feeding well [11]. In very low-birth weight (VLBW) infants, intravenous (IV) glucose infusions are started soon after birth and BG concentrations are checked promptly and frequently because of the high risk of hypo- and hyperglycaemia. 
Table 2. Signs of hypoglycaemia

\begin{tabular}{ll}
\hline Signs probably due to & Abnormal cry \\
neuroglycopenia & Irritability \\
& Lethargy \\
& Hypotonia \\
& Poor sucking \\
& Tremors/jitteriness \\
& Seizures \\
& Coma \\
\hline Signs probably due to & Pallor \\
catecholamine response & Hypothermia \\
& Sweating \\
& Tachycardia/bradycardia \\
\hline
\end{tabular}

\section{Presentation}

Hypoglycaemia can produce several non-specific signs (Table 2) [8]. However, it is important to highlight that although testing is mandatory when signs are present, many infants with neonatal hypoglycaemia are asymptomatic and only detected when the infants' BG is measured $[10,12]$.

\section{BG Measurement}

The reference standard for measuring BG is the enzymatic determination using glucose oxidase. Testing should be interpreted depending on how the sample was obtained and measured: PG is $10-12 \%$ higher than BG. It is essential to store samples in tubes with glycolysis inhibitors.

Point-of-care measurements, while readily available, are less accurate. Readings can differ up to a $10-15 \%$ from real concentrations. If hypoglycaemia requiring IV treatment is suspected on point-of-care measurement, it is ideal to confirm the result using a laboratory sample, a recommendation frequently unfulfilled $[13,14]$.

Continuous subcutaneous monitoring of interstitial glucose is feasible: in 2010, Harding's research team published a study to determine its usefulness in babies at risk of neonatal hypoglycaemia. They included 102 preterm infants $\geq 32$ weeks who were admitted to the NICU in whom they measured intermittent and continuous glucose. It was demonstrated that the continuous glucose sensor was well tolerated up to 7 days and that there was good correlation between interstitial and BG concentrations. Continuous glucose monitoring (CGM) detected more episodes of hypoglycaemia than intermittent measurements. The authors also found episodes of low glucose concentrations in babies who were tolerating full enteral feeds and who would have been otherwise excluded from screening [12]. CGM has been used mostly for research, but its successful use in VLBW infants to increase their time spent in euglycaemic range has been reported [15]. Long-term outcome of infants managed using CGM may provide a better perspective on the impact of the severity and duration of hypoglycaemia on neurodevelopment.

\section{Definitions and Incidence of Hypoglycaemia}

Ideally, a definition of hypoglycaemia should identify the true BG concentration below which irreversible changes in the brain structure and function occur. In addition, the duration of the period of hypoglycaemia required to cause harm is unknown. Thus, prevention and treatment of hypoglycaemia remain primarily empirical [16]. The use of operational thresholds for clinical management of high-risk infants appears more useful than specific BG concentrations.

There are several definitions of hypoglycaemia, some based on the presence of clinical signs, others supported by neurophysiology, [17] and still others based on our understanding of metabolism and endocrinology [7]. Endocrinologists typically suggest higher critical concentrations than those chosen by neonatologists. In 2015, the Pediatric Endocrinology Society (PES) issued guidelines for infants at risk divided into different groups according to risk factors and postnatal age. For infants without congenital hypoglycaemia disorders, they suggest maintaining PG concentrations $\geq 50 \mathrm{mg} / \mathrm{dL}$ in the first $48 \mathrm{~h}$ of life and $\geq 60 \mathrm{mg} / \mathrm{dL}$ thereafter. When disorders such as congenital hyperinsulinism are suspected or confirmed, they suggest maintaining PG concentrations $>70 \mathrm{mg} / \mathrm{dL}$ at all times [18].

Several professional associations published guidelines for the management of hypoglycaemia. The American Academy of Pediatrics proposes an operational threshold under which treatment should be considered: in asymptomatic infants in the first $4 \mathrm{~h}$ of life for a PG concentration $\leq 25 \mathrm{mg} / \mathrm{dL}$, they recommend IV therapy, and for those with PG of $25-40 \mathrm{mg} / \mathrm{dL}$, they suggest oral refeeding. Between 4- and 24-h IV therapy is recommended for PG concentrations $\leq 35 \mathrm{mg} / \mathrm{dL}$ and to refeed babies with PG between 35 and $45 \mathrm{mg} / \mathrm{dL}$. The AAP also suggests the use of a target glucose concentration of $45 \mathrm{mg} / \mathrm{dL}$ prior to 
routine feeds. Beyond the first day, levels should be maintained above $45 \mathrm{mg} / \mathrm{dL}$ [1]. The British Perinatal Medicine Association defines hypoglycaemia at one BG value $<18 \mathrm{mg} / \mathrm{dL}$ at any time, a single value $<45 \mathrm{mg} / \mathrm{dL}$ in a newborn with abnormal clinical signs or a value $<36 \mathrm{mg} /$ $\mathrm{dL}$, and remaining $<36 \mathrm{mg} / \mathrm{dL}$ at the next measurement in a baby with a risk factor for impaired metabolic adaptation but without abnormal clinical signs [19].

The population at risk for hypoglycaemia represents around $30 \%$ of all births. Fifty-one percent of at-risk infants had a hypoglycaemia event, and $19 \%$ had at least 1 episode of severe hypoglycaemia $(<36 \mathrm{mg} / \mathrm{dL})$ [20]. In a recent study, $48.7 \%$ of well-appearing infants born at $\geq 36$ weeks met their criteria for screening, with $43 \%$ of them presenting at least 1 episode of $\mathrm{BG}<50 \mathrm{mg} / \mathrm{dL}$ [21]. Moreover, Bromiker et al. [22] measured BG routinely in 4,000 healthy infants during the nadir occurring in the first hours of life (mean $74 \mathrm{~min}$ ). The incidences of BG concentrations, $<40$ and $<47 \mathrm{mg} / \mathrm{dL}$, were 3.4 and $12.1 \%$, respectively [22].

In healthy term newborns (GA 37-42 weeks), continuous interstitial glucose and intermittent PG were measured in the first 5 days of life. Thirty-nine percent of infants had $\geq 1$ episode of PG $<47 \mathrm{mg} / \mathrm{dL}$, and they would be diagnosed as hypoglycaemic using several current international recommended thresholds. These events were more frequent in early term infants (GA 37-38 weeks). The incidence of low glucose concentrations was similar in this study of healthy newborns to that found in at-risk babies from previous studies of the same group of investigators, although concentrations $<27 \mathrm{mg} / \mathrm{dL}$ were uncommon in term infants [10]. This study raised ethical issues related to research involving invasive diagnostic procedures in healthy infants. However, most involved families reported a positive experience and expressed their willingness to contribute to research in the future [23].

\section{Diagnostic Evaluation}

Most infants developing hypoglycaemia in the first days of life will not need special diagnostic assessment, except for BG concentrations and usual neonatal laboratory tests for their clinical diagnosis such as prematurity and intrauterine growth restriction [1]. However, in some situations, a consultation with an endocrinologist should be considered before hospital discharge: suspected genetic disorder, or hypoglycaemia deemed severe $(<18 \mathrm{mg} /$ $\mathrm{dL}$ any time or a needed glucose flow $\geq 10 \mathrm{mg} / \mathrm{kg} / \mathrm{min}$ ), persistent ( $>2$ measurements $<36 \mathrm{mg} / \mathrm{dL}$ within the first $48 \mathrm{~h}$ after birth), or prolonged (beyond the second day of life) $[11,18,19]$. In those cases, laboratory evaluations may include determination of insulin, cortisol, growth hormone, and eventually other metabolites depending on the individual clinical picture $[9,18]$.

\section{Consequences of Hypoglycaemia}

In 1988, Lucas et al. [24] reported their analysis of BG levels in 661 preterm infants with birth weights (BWs) $<1,850 \mathrm{~g}$ who were taking part in a multicentre study on feeding. The authors determined that PG concentrations $<47 \mathrm{mg} / \mathrm{dL}$ for 5 or more days (including many infants with asymptomatic hypoglycaemia) were associated with serious cognitive and motor development impairments at 18 months corrected age [24]. Although the study was not originally designed to evaluate hypoglycaemia and it only included low-BW infants, as a result of its publication, many neonatologists considered that the PG concentration of $47 \mathrm{mg} / \mathrm{dL}$ should be treated to prevent long-term complications in term and preterm newborns. Subsequently, many studies reported that hypoglycaemia, even when asymptomatic, is associated with adverse neurodevelopmental outcomes. In a series of 1,395 infants (23-42 weeks) born at the University of Arkansas in 1998, BG was measured routinely within the first $3 \mathrm{~h}$ of life. Their academic achievements at 4 th grade examinations were matched with the results of the BG concentrations. There was an association of transient hypoglycaemia and lower scores with school performance tests. However, it is not clear from the study in how many of those patients there were other factors associated such as low GA [25].

A systematic review published in 2019 included 9 cohort studies involving 4,041 infants with a GA $>32$ weeks. Neonatal hypoglycaemia was associated with specific cognitive deficits at ages $2-5$ years, including greater risk of visual motor coordination disorders and executive dysfunction. In later childhood (6-11 years), there was twice the risk of problems in literacy and numeracy [26].

In contrast to these findings, other studies showed good outcomes at follow-up of hypoglycaemic neonates. In an observational study of 566 preterm infants $(<32$ weeks) born between 1990 and 1991 in Northern England, BG was measured daily during the first 10 days of life. Of these, 47 presented hypoglycaemia $(<47 \mathrm{mg} / \mathrm{dL})$ on $\geq 3$ days. Psychometric tests performed at 2 and 15 years were compared with those of a control group. The 
authors found no impact on neurodevelopment even in infants who had developed severe or prolonged hypoglycaemia [27].

A secondary analysis of a study conducted by the Infant Health and Development Program (USA) compared preterm infants with various degrees of neonatal hypoglycaemia with those of normoglycaemic controls at 3-18 years. Even patients with severe hypoglycaemia had no increase in neurodevelopmental problems at age 18 years [28].

The New Zealand group led by Jane Harding published in 2015, a study of 404 infants of a GA $\geq 35$ weeks with risk factors who presented hypoglycaemia $(<47 \mathrm{mg} /$ $\mathrm{dL}$ ), many cases, not diagnosed by traditional methods but by monitoring interstitial glucose concentrations, did not demonstrate neurodevelopmental impairment at 2 years. They also found that rapid correction of hypoglycaemia by IV infusions sometimes led to hyperglycaemia and that this glucose instability was associated with a worse neurological outcome [29]. The same cohort of children was re-evaluated at 4.5 years. They did not have an increased rate of severe neurological deficits but demonstrated problems in executive function, attention control, motor-visual coordination, and possibly an increased risk of hyperactivity [30].

In summary, the information suggests that episodes of neonatal hypoglycaemia and particularly those that are more profound and prolonged can be associated with important neurodevelopmental sequelae. Unfortunately, the BG concentration requiring therapy remains uncertain, and it is not clear which infants could benefit from oral treatment and which need immediate IV administration of glucose.

\section{How Long to Control BG in Premature Babies?}

It is important to know that although in the population at risk, we usually monitor BG concentrations in the first days, premature newborns, particularly those with VLBW, can present episodes of hypoglycaemia for prolonged periods, sometimes until term-corrected age. Studies measuring interstitial BG in apparently healthy VLBW infants show frequent episodes during which their glucose concentrations are in either the hypo- or hyperglycaemic range. These episodes commonly occur during fasting and postprandial periods. However, concentrations above and below those considered normal have not been shown to be harmful for these patients [31, 32].

\section{Oral Prevention and Treatment}

In term infants at risk and late preterm infants with adequate feeding skills, early breastfeeding should be encouraged and formula or gel administered as treatment. Since breast milk might be scarce in mother during the first hours of life of the infant, breastfeeding alone cannot be recommended as the treatment of hypoglycaemic events. If breast milk is not available due to insufficient supply or mothers' choice, donor human milk or formula is a suitable alternative [33].

In recent years, several studies were published on treatment and prevention of hypoglycaemia using $40 \%$ dextrose gel. Its administration at $200 \mathrm{mg} / \mathrm{kg}$ to the oral mucosa of hypoglycaemic infants decreased the need for admission to the neonatal unit for IV treatment and resulted in greater success in breastfeeding at 2 weeks [34]. At the follow-up at 2 years, the use of dextrose gel was not associated with additional risks [35].

A 2016 Cochrane review confirms those findings and supports considering dextrose gel as the first-line treatment for infants with neonatal hypoglycaemia [36]. The use of dextrose gel to prevent hypoglycaemia in neonatal at-risk groups is controversial. A placebo-controlled dose-finding study in 416 infants showed good response to a single dose of $200 \mathrm{mg} / \mathrm{kg}$ [37].

However, a pilot study with a quasi-experimental design found no benefit. Their different results may be due to the use of a commercially available $77 \%$ gel, instead of the $40 \%$ gel used in other publications [38].

\section{Treatment}

When hypoglycaemia is severe or prolonged or when the oral route is contraindicated, the newborn should be admitted and IV glucose administered. A mini bolus of $200 \mathrm{mg} / \mathrm{kg}$ can be used followed by a constant glucose administration of $5-8 \mathrm{mg} / \mathrm{kg} / \mathrm{min}$ [39]. Slower infusions can be used in infants of diabetic mothers to avoid excessive stimulation of insulin production. Given the frequent episodes of hyperglycaemia resulting from the mini bolus, an alternative is to directly start with a continuous infusion at the rates explained earlier [31]. It was shown as early as 1980 that newborns reached similar PG concentrations in 20-30 min compared to those who received the mini bolus [39].

Glucocorticoids, glucagon, and diazoxide have been occasionally used in very severe cases and those resistant to treatment. It is difficult to determine postnatal age- 
specific BG concentrations to start IV treatment. In 2020, a study from the Netherlands evaluated the neurodevelopment at 18 months of 689 otherwise healthy infants of a GA $\geq 35$ weeks with a BW $\geq 2,000$ g at risk for hypoglycaemia randomized to 2 groups: 1 group received treatment upon reaching a threshold of $47 \mathrm{mg} / \mathrm{dL}$ and the other group at $36 \mathrm{mg} / \mathrm{dL}$. The group in which lower PG concentrations were tolerated had more severe hypoglycaemic events but less diagnostic tests and invasive treatments. Both groups had similar neurodevelopmental results at 18 months. They concluded that starting treatment at the lower threshold $(36 \mathrm{mg} / \mathrm{dL})$ is safe. These results should be interpreted cautiously since there were serious adverse events in the lower threshold group and there is no comparison with normoglycaemic controls [40]. Furthermore, this conclusion cannot be extrapolated to patients with suspected endocrine or metabolic disorders [41]. Neurodevelopmental problems may only appear later in life, as we previously described $[25,30$, 42].

In his thoughtful commentary, Barrington discussed the difficulty of achieving a balance between over-screening and over-treating versus eventually under-treating. The potential excess in admissions, evaluations, and therapy implies "collateral damages" seldom taken into account such as pain, psychological impact in the parents, and less successful breastfeeding [43].

\section{The Guidelines for Diagnosis, Therapy, and the Medico-Legal Dilemma}

The guidelines that have been produced by several professional associations are based on weak evidence and recommend a range of values that differ between them. No guideline has been prospectively researched prior to its release to determine the risks and benefits of its implementation. We would prefer to await the evidence, but meanwhile, infants are still being born and develop hypoglycaemia. As neonatologists, we are forced to choose a standardized protocol or design one of our own to follow at our institution as a support for our management of these infants.

Unfortunately, we not only have the uncertainty about the minimum concentration resulting in harm but we are also exposed to malpractice lawsuits. Lucas et al.'s [24] study set a precedent both medically and legally, associating long-term adverse outcomes in infants with moderate hypoglycaemia, even in the absence of scientific evidence supporting this assertion.

Neonatal Hypoglycaemia:

A Never-Ending Story?
Malpractice trials involving children with neurodevelopmental delay or cerebral palsy often focus on the management of an episode of hypoglycaemia, rather than taking into account that in many cases, hypoglycaemia is associated with other medical conditions that also can cause these impairments [44]. To reduce the risk of litigation, a detailed physical examination of the newborn with hypoglycaemia, the BG concentration, the method by which it was measured, and the decision taken for management should be clearly documented, specifying the response to therapy [45]. Discussing with parents the controversies surrounding therapeutic decisions could help reduce litigation risks [46].

\section{Conclusions}

A large number of both normal newborns and the subpopulation at higher risk develop hypoglycaemic episodes. The guidelines from professional associations propose investigation of hypoglycaemia in high-risk groups. We must be aware that this involves making heel or venous punctures to draw blood in up to $30 \%$ of newborns. It is important to understand that many of these children have no indication for treatment and we will be treating many others without knowing that therapy is beneficial.

Unfortunately, the dilemma continues: we know that neonatal hypoglycaemia can lead to neurodevelopmental disorders. The use of operational thresholds to start therapy may result in a decrease in the number of events of BG concentrations resulting in neuroglycopenia. However, studies to date have not conclusively demonstrated that treating asymptomatic hypoglycaemia significantly improves neurological prognosis. We also do not have certainty about the most appropriate concentration at each moment of infants' life to start IV treatment. Worse still is that unnecessary hospitalization, episodes of hyperglycaemia, and instability generated by IV glucose administrations can be harmful. However, we should recognize that providing guidance where evidence is lacking could at least raise awareness and lead to further research.

Evaluation at school age of children from RCTs in whom different thresholds for treatment had been assigned, comparisons of IV treatment at different rates with and without a previous mini bolus, and impact of clinical use of continuous interstitial glucose monitoring are among the areas that should be explored. Until these or other studies are developed, the chronicle of neonatal hypoglycaemia still appears to us like a never-ending story. 


\section{Acknowledgements}

The authors thank Dr. Peter Davis for detailed and thoughtful review, Dr. Gonzalo Mariani for advice, and Drs. Ines Urquizu and Laura Konikoff for English review.

\section{Conflicts of Interest Statement}

N.E.V. has received in the past teaching honorariums from Abbvie. F.C. has no conflicts of interest to declare.

\section{Funding Sources}

There was no funding for the development of the review.

\section{Author Contributions}

N.E.V. wrote the first draft, organized the manuscript, and performed the first bibliographical search. F.C. added sections to the original draft, completed the bibliography, and reviewed all references. Both authors reviewed and approved the manuscript before submission.

\section{References}

1 Committee on Fetus and Newborn; Adamkin DH, Adamkin DH. Postnatal glucose homeostasis in late-preterm and term infants. Pediatrics. 2011;127(3):575-9.

2 Cornblath M, Ichord R. Hypoglycemia in the neonate. Semin Perinatol. 2000;24(2):136-49.

3 Hattersley AT, Beards F, Ballantyne E, Appleton M, Harvey R, Ellard S. Mutations in the glucokinase gene of the fetus result in reduced birth weight. Nat Genet. 1998 Jul;19(3):26870.

4 Stanley CA, Rozance PJ, Thornton PS, De Leon DD, Harris D, Haymond MW, et al. Reevaluating "transitional neonatal hypoglycemia": mechanism and implications for management. J Pediatr. 2015 Jun;166(6):1520-5. e1.

5 Srinivasan G, Pildes RS, Cattamanchi G, Voora S, Lilien LD. Plasma glucose values in normal neonates: a new look. J Pediatr. 1986; 109(1):114-7.

6 Hoseth E, Joergensen A, Ebbesen F, Moeller M. Blood glucose levels in a population of healthy, breast fed, term infants of appropriate size for gestational age. Arch Dis Child Fetal Neonatal Ed. 2000;83(2):F117-9.

7 Harding JE, Harris DL, Hegarty JE, Alsweiler JM, McKinlay CJ. An emerging evidence base for the management of neonatal hypoglycaemia. Early Hum Dev. 2017;104:51-6.

8 Thompson-Branch A, Havranek T. Neonatal hypoglycemia. Pediatr Rev. 2017;38(4):14757.

9 Adamkin DH. Metabolic screening and postnatal glucose homeostasis in the newborn. Pediatr Clin North Am. 2015;62(2):385-409.

10 Harris DL, Weston PJ, Gamble GD, Harding JE. Glucose profiles in healthy term infants in the first 5 days: the glucose in well babies (GLOW) Study [published online ahead of print, 2020 May 4]. J Pediatr. 2020;223:34-41.e4.

11 Deshpande S, Ward Platt M. The investigation and management of neonatal hypoglycaemia. Semin Fetal Neonatal Med. 2005 10(4):351-61.

12 Harris DL, Battin MR, Weston PJ, Harding JE. Continuous glucose monitoring in newborn babies at risk of hypoglycemia. J Pediatr. 2010;157(2):198-e1.
13 Dixon KC, Ferris RL, Marikar D, Chong M, Mittal A, Manikam L, et al. Definition and monitoring of neonatal hypoglycemia: a nationwide survey of NHS England neonatal units. Arch Dis Child Fetal Neonatal Ed. 2017;102(1):F92-F93.

14 Roth-Kleiner M, Stadelmann Diaw C, Urfer J, Ruffieux C, Werner D. Evaluation of different POCT devices for glucose measurement in a clinical neonatal setting. Eur J Pediatr. 2010; 169(11):1387-95.

15 Galderisi A, Facchinetti A, Steil GM, OrtizRubio P, Cavallin F, Tamborlane WV, et al. Continuous glucose monitoring in very preterm infants: a randomized controlled trial. Pediatrics. 2017;140(4):e20171162.

16 Hay WW Jr, Raju TN, Higgins RD, Kalhan SC, Devaskar SU. Knowledge gaps and research needs for understanding and treating neonatal hypoglycemia: workshop report from Eunice Kennedy Shriver national institute of child health and human development. J Pediatr. 2009;155(5):612-7.

17 Koh TH, Aynsley-Green A, Tarbit M, Eyre JA Neural dysfunction during hypoglycaemia. Arch Dis Child. 1988;63(11):1353-8.

18 Thornton PS, Stanley CA, De Leon DD, Harris D, Haymond MW, Hussain K, et al. Recommendations from the pediatric endocrine society for evaluation and management of persistent hypoglycemia in neonates, infants, and children. J Pediatr. 2015;167(2):238-45.

19 Hawdon JM. Identification and management of neonatal hypoglycemia in the full-term infant. British Association of perinatal medicine framework for practice, 2017. I Hum Lact. 2019;35(3):521-3.

20 Harris DL, Weston PJ, Harding JE. Incidence of neonatal hypoglycemia in babies identified as at risk. J Pediatr. 2012;161(5):787-91.

21 Mukhopadhyay S, Wade KC, Dhudasia MB, Skerritt L, Chou JH, Dukhovny D, et al. Clinical impact of neonatal hypoglycemia screening in the well-baby care [published online ahead of print, 2020 Mar 9]. J Perinatol. 2020 Sep;40(9):1331-8.
22 Bromiker R, Perry A, Kasirer Y, Einav S, Klinger G, Levy-Khademi F. Early neonatal hypoglycemia: incidence of and risk factors. A cohort study using universal point of care screening. J Matern Fetal Neonatal Med. 2019;32(5):786-92.

23 Cumberpatch AR, Weston PJ, Harding JE, Harris DL. Parents of babies who participated in an invasive clinical study report a positive experience: the glucose in well babies (GLOW) study. Arch Dis Child Fetal Neonatal Ed. 2020;105(1):4-7.

24 Lucas A, Morley R, Cole TJ. Adverse neurodevelopmental outcome of moderate neonatal hypoglycaemia. BMJ. 1988;297(6659): 1304-8.

25 Kaiser JR, Bai S, Gibson N, Holland G, Lin TM, Swearingen CJ, et al. Association between transient newborn hypoglycemia and fourth-grade achievement test proficiency: a population-Based Study. JAMA Pediatr. 2015;169(10):913-21.

26 Shah R, Harding J, Brown J, McKinlay C. Neonatal glycaemia and neurodevelopmental outcomes: a systematic review and meta-analysis. Neonatology. 2019;115(2):116-26.

27 Tin W, Brunskill G, Kelly T, Fritz S. 15-year follow-up of recurrent "hypoglycemia" in preterm infants. Pediatrics. 2012;130(6): e1497-503.

28 Goode RH, Rettiganti M, Li J, Lyle RE, Whiteside-Mansell L, Barrett KW, et al. Developmental outcomes of preterm infants with neonatal hypoglycemia. Pediatrics. 2016;138(6): e20161424.

29 McKinlay CJ, Alsweiler JM, Ansell JM, Anstice NS, Chase JG, Gamble GD, et al. Neonatal glycemia and neurodevelopmental outcomes at 2 years. N Engl J Med. 2015;373(16): 1507-18.

30 McKinlay CJD, Alsweiler JM, Anstice NS, Burakevych N, Chakraborty A, Chase JG, et al. Association of neonatal glycemia with neurodevelopmental outcomes at 4.5 years. JAMA Pediatr. 2017;171(10):972-83. 
31 Mola-Schenzle E, Staffler A, Klemme M, Pellegrini F, Molinaro G, Parhofer KG, et al. Clinically stable very low birthweight infants are at risk for recurrent tissue glucose fluctuations even after fully established enteral nutrition. Arch Dis Child Fetal Neonatal Ed. 2015; 100(2):F126-31.

32 Pertierra-Cortada A, Ramon-Krauel M, Iriondo-Sanz M, Iglesias-Platas I. Instability of glucose values in very preterm babies at term postmenstrual age. J Pediatr. 2014;165(6): 1146-e2.

33 Harris DL, Weston PJ, Battin MR, Harding JE. A survey of the management of neonatal hypoglycaemia within the Australian and New Zealand neonatal network. J Paediatr Child Health. 2014;50(10):E55-62.

34 Harris DL, Weston PJ, Signal M, Chase JG, Harding JE. Dextrose gel for neonatal hypoglycemia (the Sugar Babies Study): a randomised, double-blind, placebo-controlled trial. Lancet. 2013;382(9910):2077-83.

35 Harris DL, Alsweiler JM, Ansell JM, Gamble GD, Thompson B, Wouldes TA, et al. Outcome at 2 years after dextrose gel treatment for neonatal hypoglycemia: follow-up of a randomized trial. J Pediatr. 2016;170:54-2.
36 Weston PJ, Harris DL, Battin M, Brown J, Hegarty JE, Harding JE. Oral dextrose gel for the treatment of hypoglycaemia in newborn infants. Cochrane Database Syst Rev. 2016; 5(5):CD011027. Published 2016 May 4.

37 Hegarty JE, Harding JE, Gamble GD, Crowther CA, Edlin R, Alsweiler JM. Prophylactic oral dextrose gel for newborn babies at risk of neonatal hypoglycaemia: a randomised controlled dose-finding trial (the Pre-hPOD Study). PLoS Med. 2016;13(10):e1002155. Published 2016 Oct 25.

38 Coors SM, Cousin JJ, Hagan JL, Kaiser JR. Prophylactic dextrose gel does not prevent neonatal hypoglycemia: a Quasi-Experimental Pilot Study. J Pediatr. 2018;198:156-61.

39 Lilien LD, Pildes RS, Srinivasan G, Voora S, Yeh TF. Treatment of neonatal hypoglycemia with minibolus and intraveous glucose infusion. J Pediatr. 1980;97(2):295-8.

40 van Kempen AAMW, Eskes PF, Nuyteman DHGM, van der Lee JH, Dijksman LM, van Veenendaal NR, et al. Lower versus traditional treatment threshold for neonatal hypoglycemia. N Engl J Med. 2020;382(6):534-44.
41 Thornton PS, De Leon DD, Sperling MA. Treatment threshold for neonatal hypoglycemia. N Engl J Med. 2020;382(23):2272.

42 Roeper M, Kummer S, Meissner T. Treatment threshold for neonatal hypoglycemia. N Engl J Med. 2020;382(23):2273.

43 Barrington K. Glucose screening and treatment in the newborn; what now? Available from: https://neonatalresearch.org/2020/ 05/07/glucose-screening-and-treatment-inthe-newborn-what-now/. Accessed 2020 Sep 16.

44 Fanaroff JM, Goldsmith JP. The most common patient safety issues resulting in legal action against neonatologists. Semin Perinatol. 2019;43(8):151181.

45 Williams AF. Neonatal hypoglycemia: clinical and legal aspects. Semin Fetal Neonatal Med. 2005;10(4):363-8.

46 Hawdon JM, Beer J, Sharp D, Upton M. NHS improvement patient safety programme "reducing term admissions to neonatal unit". Neonatal hypoglycaemia: learning from claims. Arch Dis Child Fetal Neonatal Ed. 2017;102(2):F110-F115. 